\title{
El fenómeno 2.0 en el sector turístico. El caso de Madrid 2.0
}

\section{Trinidad Domínguez Vila ${ }^{i}$ Noelia Araújo Vila ii}

\author{
Univesidad de Vigo (España)
}

\begin{abstract}
Resumen: Hoy en día, en la mayoría de los ámbitos, Internet es un elemento clave para cualquier actividad, que cambia continuamente y que requiere una actualización constante. Una de las últimas evoluciones ha dado como resultado la web 2.0, que permite la interacción directa y la retroalimentación con el usuario, siendo su principal eje la publicación de opiniones e intercambio de informaciones. El sector turístico, al igual que toda la sociedad, también se ha visto envuelto en dichos cambios, presentándosele una oportunidad y una ventaja competitiva al poder trabajar con herramientas que posibilitan la comunicación directa. Una de las grandes apuestas ha sido la realizada por la Comunidad de Madrid a través de su web www.turismomadrid.es. En este trabajo se busca analizar el papel actual que Internet, la Web 2.0 y principalmente las redes sociales, están jugando en relación al turismo, para posteriormente poder comprobar a través de una comparativa con las webs turísticas de otras comunidades, si el caso de Madrid se muestra como el principal modelo de estrategia proactiva, tal como se recoge en sus objetivos iniciales.
\end{abstract}

Palabras clave: Promoción turística; Web 2.0; Redes sociales; Blog; MadridTurismo.

Title: The phenomenon 2.0 in the Tourism sector. Madrid 2.0 case

Abstract: Today, Internet is a key element in any activity that is constantly changing and requires constant updating. One of the latest developments has been the web 2.0, which allows direct interaction and feedback to the user, being its main focus the publication of opinions and exchange of information. The Tourism Sector, like any society, has also been involved in these changes, presenting an opportunity and a competitive advantage to be working with tools to communicate with the user. One of the big bets has been made by Madrid Community, through its web www.turismomadrid.es. This paper seeks to analyze the current role of Internet, Web 2.0 and social networks and the role they are playing in relation to tourism and to verify through a comparison with tourist sites in other communities, whether Madrid case is shown as the principal model of proactive strategy, like they wanted on the initial objectives.

Keywords: Tourism promotion; Web 2.0; Social networking; Blog; MadridTurismo.

i Doctora del Departamento de Organización de Empresas y Marketing de la Universidad de Vigo. E-mail: trinidad@uvigo.es ii Personal investigador del Departamento de Organización de Empresas y Marketing de la Universidad de Vigo. E-mail: naraujo@uvigo. es 


\section{Introducción}

En pleno siglo XXI el hablar de nuevas tecnologías e Internet no es ninguna novedad, dado que son herramientas que forman parte del día a día en nuestra sociedad, tanto en el ámbito personal como profesional. La novedad ya no está en el acceso a infinidad de información a través de estas vías, sino, en la búsqueda de modos de gestionarla y hacerla atractiva para los usuarios. En esta realidad, en la que los internautas están anegados ante el exceso de información que reciben, surge el fenómeno 2.0, el cual busca la interacción con el usuario vinculándolo con los sitios webs a los que accede y convirtiendo éstos en atractivos. El fenómeno 2.0 engloba una serie de herramientas (redes sociales, blogs, marcadores sociales o galerías de imágenes, entre otros), en las que las empresas del entorno actual deben estar presentes si quieren sobrevivir y llegar a sus clientes potenciales. Por ello, el sector turístico no se ha quedado atrás, y diversas empresas y organismos del mismo, desde PYMES o pequeños Ayuntamientos a grandes multinacionales o grandes ciudades, ya se han subido a la denominada Tercera Ola o Era Digital. Muestra de ello es la estrategia promocional seguida por la ciudad de Madrid desde inicios del año 2009, referente a nivel nacional e internacional, que a través de su web 2.0 publicita y gestiona todos los eventos culturales, turísticos o de ocio, entre otros, haciendo al usuario de las distintas herramientas 2.0 partícipe en los mismos. Por ello, el presente artículo parte de una revisión teórica sobre la evolución y el papel actual de las nuevas tecnologías y su vinculación con el sector turístico, para a continuación realizar un estudio cualitativo, a través de la técnica de análisis de contenido, de las herramientas promocionales utilizadas por la comunidad de Madrid dentro del fenómeno turismo 2.0. Dicho análisis, se complementa con la comparativa con otras comunidades españolas destacadas por su promoción y gestión turística a través del mundo 2.0. El objetivo del trabajo, es conocer cuál es la estrategia seguida por la comunidad de Madrid ante dicho fenómeno (turismo 2.0) y comprobar si realmente es la comunidad española que se encuentra a la cabeza en promoción turística 2.0 .

\section{Nuevos canales de comunicación: de las conversa-} ciones al chat

Hoy en día, queda claro que Internet supuso y supone una inmensa revolución sistematizada ya en el día a día de las personas. Es obvio que no es una tendencia pasajera, sino que su uso, interiorización y dependencia de gran parte de la población, empresas y organismos, ha dado lugar a una serie de cambios ya palpables en la sociedad y "el estar conectado" es de vital importancia. Internet se ha convertido así en el medio por excelencia para el intercambio de información entre individuos independientemente de su localización geográfica (Kahn, Leiner, Cerd, Clark, Kleinrock, Lynch, Postel, Roberts y Wolff, 1997:129). Así, ya es habitual el hablar de: Nueva Economía, Sociedad de la Información, Era Digital, Economía de Red o Tercera Ola.

Tras sus inicios en las décadas de 1960-1970 como herramienta del departamento de defensa de USA (Kahn et $a l, 1997)$, en la década de 1980 se empieza a expandir a nivel mundial de modo comercial, facilitando el conocimiento de la World Wide Web - "www"- en los noventa. En 1999, la cifra de usuarios ya superaba los 147 millones a nivel mundial (Computer Industry Almanac, 1999). Internet pasó por tanto a convertirse en un medio de masas, es decir, un soporte de comunicación plural con diversas formas de conexión interpersonal (Morris y Ogan, 1996).

A finales de la década del 2000, en España, el 56,5\% de las personas mayores de 10 años habían utilizado alguna vez Internet durante el año 2007, es decir, 22.850.000 personas, situando a España en el sexto puesto en el ranking europeo (Fundación Orange, 2008). Datos más actuales, reflejan que el 58\% de los españoles usan Internet de lunes a domingo, a través del portátil, PC, móvil o PDA (Mediascope Europe, 2010). El 26,9\% de la población española mayor de 14 años puede considerarse internauta (Asociación para la Investigación de los Medios de Comunicación -AIMC-, 2008), entendiendo por internauta "usuario de una red informática de comunicación" o "usuario experto de Internet" (Diccionario de Internet, 2002: 222), entre las definiciones más comunes. Estas cifras reflejan que el número de usuarios de Internet está incrementándose, especialmente si se toma como referencia las nuevas generaciones, donde el 89\% de los jóvenes -entre 16 y 24 años- son usuarios (Mediascope Europe, 2010).

Cuando se habla de usuarios de Internet, nos referimos a consumo de Internet desde diferentes soportes, ya no sólo desde un ordenador personal, apareciendo así lo que podemos denominar "nuevas pantallas", definidas como "PCs, móviles y PDAs, entre otros" (Murolo, 2009). $\mathrm{Al}$ fenómeno de Internet, como red de redes, se unen los avances tecnológicos en cuanto a los soportes de consumo y uso del mismo, pasando del ordenador, a los móviles de tercera generación, PDAs, iPods, televisores digitales, consolas o términos que escapan al alcance de numerosos segmentos del mercado, como los tabletPC o los webPads -dispositivos que permiten la navegación por la web, similares a los TabletPC, pero mucho más ligeros y con pantallas menores-. Se crea por tanto una red socio-cultural donde la gente puede satisfacer las necesidades informativas e interactivas a través de los medios citados, aunque estas nuevas vías de comunicación difieran de la tradicional comunicación cara a cara, mostrando, por ejemplo, problemas de coordinación debido a la falta de retroalimentación o ausencia de señales durante una discusión (Papacharissi y Rubin, 2000). Aún así, el consumo de Internet aumenta, siendo para muchos una continuación de la tradicional presencia social, la cual se consideraba signo de existencia y un intercambio de comunicación cálido, sensible, personal y activo (Short, Ederyn y Christie, 1976). Actualmente, es especialmente la gente joven la que se hace notar a través de este medio, sector en el que se hace más presente. 
Independientemente de la edad, Internet es un medio usado por gran porcentaje de la población siendo el uso más generalizado la búsqueda de información (95\%), seguida por el correo, y donde el soporte estrella sigue siendo el ordenador personal. En los últimos años han aparecido nuevas tendencias, entre las que se encuentran jugar, solucionar problemas, relajarse, estar entretenido, aprender cosas (Flanagin y Metzger, 2001: 162-163) o leer prensa y diarios, descargar películas y/o música, escuchar la radio, realizar compras o reservar viajes entre otros, y especialmente, la participación en foros, chats, blogs, mensajería instantánea o llamadas (messenger, skype) y redes sociales, con todo lo que su uso implica (ver fotos, vídeos, podcasts, etc.), pudiéndose resumir como todo aquello que rodea al fenómeno de la web 2.0 o comunicación 2.0 -ver gráfico 1- (Zed digital, 2008).

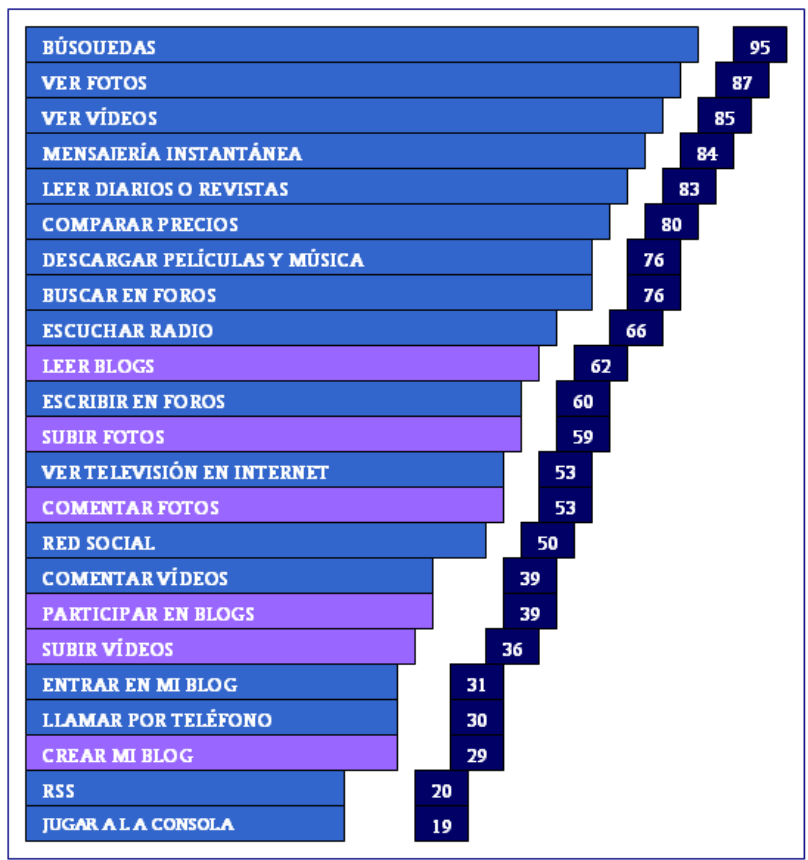

por lo que se opta por agruparlas para facilitar la segmentación de los internautas según su uso y la importancia de las mismas, como se puede observar en el gráfico 2. Las funciones principales serían estructuradas en: espacios para ver, compartir y descargar, wikis, weblogs, tiendas, marcadores sociales y redes.

Se puede estimar en un $45.8 \%$ el número de internautas que utilizan los servicios relacionados con la Web 2.0 (Fundación Orange, 2008). E incluso, ya se han publicado datos que segmentan y caracterizan a los usuarios de este mercado en función de su actividad. Se estructuran a través de una escala que va desde los más activos a los pasivos, donde las principales categorías son (Forrester Research, 2009):

- Creadores: publican en blogs y/o webs, suben fotos, vídeos y similares.

- Críticos: publican comentarios, valoraciones y contribuyen en foros.

- Lectores: utilizan suscripciones, etiquetan fotos y participan en procesos de votación.

- Registrados: visitan y mantienen su perfil de usuario en comunidades.

- Espectadores: leen blogs, foros, ven vídeos, escuchan podcasts, etc.

- Inactivos: no realizan ninguna de las actividades enumeradas anteriormente.

Si se parte de la edad para la segmentación de usuarios de la Web 2.0, se observa que la gente más joven centra el uso de Internet en las redes sociales (facebook, tuenti) y wikis. Los mayores de 26 en los weblogs -sitio web que es una mezcla entre un foro y un blog (Diccionario de Internet, 2002), -blogger, fotolog-, y los de edades comprendidas entre 31 y 35 en comparativas de precio/tiendas (ebay, amazon). El consumidor en general, independientemente de la edad, opta por sitios donde compartir y descargar vídeos, fotos y películas, como Youtube o Google (Zed digital, 2008). En cambio, si la segmentación es ejecutada en base a la clase social, destaca lo que se puede denominar "clase social más alta", ya que se desmarca de los usos habituales, apostando por marcadores sociales, como del.
Gráfico 1: Principales usos sociales en Internet (\%). Fuente: elaboración propia a partir de Zed digital 2008

Una vez establecido el contexto que rodea a la Web 2.0, ya se puede realizar un estudio más pormenorizado de la misma. Las definiciones que la Web 2.0 recibe son variadas, siendo las características comunes a todas ellas la conectividad, participación, intereses comunes, pertenencia, identidad y relaciones (Castells, 2006), y donde sus principios vienen determinados por la inteligencia colectiva, el protagonismo de los clientes, las relaciones entre usuarios y la generación de conocimiento colectivo (Instituto Tecnológico Hotelero (ITH), Sociatec y Canal Empresarial, 2009).

Son muchas y diversas las herramientas que la Web 2.0 pone a disposición del usuario,

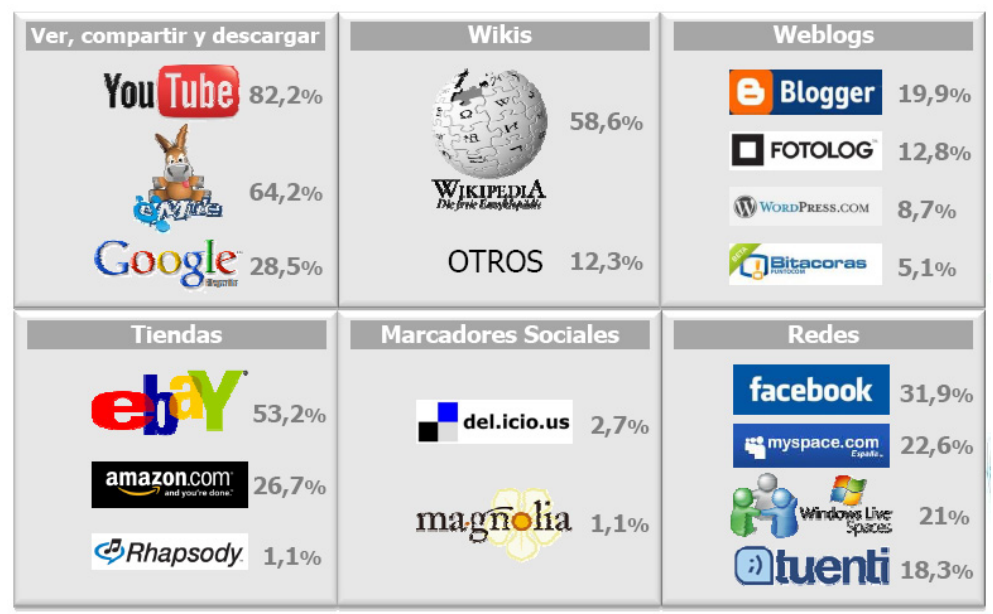

Gráfico 2: Herramientas de la Web 2.0. Fuente: Zed digital 2008 
icio.us, webgenio, y tagging - del inglés, tag, etiqueta- , o bookmarking social.

Como ya se ha comentado y se ha podido observar anteriormente, las redes sociales son uno de los elementos clave y de mayor incidencia en la Web 2.0- Las redes sociales son un fenómeno que ha evolucionado de modo exponencial en los últimos años, a pesar de su reciente creación casi en el siglo XXI, ya que la primera red social reconocida como tal es Six Degrees, que estuvo operativa desde 1997 a 2001. Precisamente, dicha red debe su nombre a la teoría de los "seis grados de separación", iniciada intuitivamente por Karinthy, en 1929, según la cual sólo es necesario un pequeño número de enlaces para conectar a cualquier persona con el resto de la población. Esta teoría fue respaldada e investigada por diversos autores (De Sola Pool y Kochen, 1978; Watts y Strogatz, 1998), hasta que en 2001, Watts, tras varios experimentos, llegó a la conclusión de que "la media de intermediarios entre dos personas cualesquiera a escala mundial es de seis" (Watts, 2006: 9).

Las redes sociales, dado sus inicios, se pueden considerar incluso anteriores a la Web 2.0, entrando en un proceso que las ha llevado a integrarse como parte de este fenómeno. En gran medida se debe a sus características, hoy también reconocidas en todo lo que rodea la Web 2.0: conectividad, opinión, participación o relaciones, entre otras.

Tras su aparición en 1997, el boom o uso masivo, se dio entre 2002 y 2003, años de creación de la gran mayoría de ellas, y que actualmente aún están en uso, como es el caso de Flicker, Myspace o Facebook. De ahí que desde su aparición a nuestros días, el interés por su estudio no haya hecho más que crecer, especialmente por parte de los sociólogos, dado su componente social (Holme, Edling y Liljeros, 2004).

Pero, ¿qué entendemos por red social? Se pueden definir como "la última herramienta de comunicación en línea que permite a los usuarios crear un perfil público o semi-público, crear y ver sus propias redes, así como de otros usuarios, e interactuar con la gente en sus redes" (Subrahmanyaman, 2008: 421). Concretando, las características comunes a toda red o herramientas de las redes sociales pueden ser unificadas en (Zamora, 2006):

- Perfiles visibles o semivisibles.

- Intercambio de ficheros (fotos, vídeos).

- Intercambio de información.

- Capacidad de crear nuevos enlaces y modos de conexión en línea.

- Interconectividad entre usuarios (comentarios en red). Su éxito y aceptación ha sido tal en la sociedad actual, que el $50 \%$ de los internautas son usuarios de redes sociales, el $38 \%$ las conoce y no las utiliza y tan sólo el $12 \%$ no conoce su existencia. De sus usuarios, en España, el $46,47 \%$ se conecta cuando llega a casa a la tarde/noche, el $40,42 \%$ los fines de semana y el $38,53 \%$ en cualquier momento, especialmente los jóvenes que lo hacen varias veces al día, incluso en huecos de trabajo. Las acciones favoritas en las redes son subir/compartir fotos (70,9\%), mandar mensajes privados $(62,07 \%)$, comentar fotos $(55,01 \%)$ o actualizar el perfil $(52,14 \%)$, seguidas de mandar mensajes públicos, cotillear o etiquetar a amigos en las fotos (Zed digital, 2008).

A nivel mundial, el uso de redes se ha convertido en un fenómeno revolucionario, llegando a niveles de consumo de 5 horas y media al mes (The Nielsen Company, 2010). Destaca también el uso acentuado de los menores de 25 años, de los cuales, en lo que respecta a las redes Facebook y Twitter, el 19\% permanece conectado casi todo el día, el $27 \%$ se conecta sólo de vez en cuando y el $32 \%$ tan pronto como se levanta (Retrevo, 2010)

Precisamente, Facebook ha llegado a la cima siendo actualmente la red más importante, teniendo ya $400 \mathrm{mi}$ llones de usuarios (Retrevo, 2010), lo que equiparándolo con un país, la convertiría en el tercer país del mundo más poblado, superado sólo por China e India. En España, al igual que en el resto del mundo, la red más utilizada es Facebook (63,85\%), seguida de Myspace (45,28\%), Windows Live (42,11\%), Tuenti $(36,54 \%)$ y Hi5 $(36,44 \%)$-tabla 1-. Lo habitual es que una persona utilice más de una, siendo la media de 2,67. Obviamente, cada red tiene sus propias características que determinan el tipo de usuario, los modelos de comportamiento y la propia difusión y conocimiento de la red social, como se puede observar en la siguiente tabla, donde se realiza un estudio de las más relevantes.

Esta amplitud de redes, ha dado origen a establecer pautas de comportamiento comunes entre distintos perfiles de usuarios, donde las categorías establecidas son (Best Relations, 2009):

- - Famoso: personajes del mundo de la política, moda, artes, cine...que cuentan con perfil en alguna red social.

- - Líder: perfiles muy activos, 24 horas conectados. Gran cantidad de contactos y mucha interacción.

- - Fotógrafos o artistas: autopromocionan su obra, en la mayor parte fotográfica, aunque también hay músicos, ilustradores...

- - Mariposas sociales: buscan relaciones afectivo-sexuales y pueden ir desde la amistad y el flirteo al contacto físico.

- - Reporteros: cuentan sus experiencias, su vida y deseos.

- - Viajeros: comparten información sobre experiencias de sus viajes.

- - Desconfiados: perfiles poco activos. Grupo pequeño de amigos y poca interacción.

- - Mirones: perfiles semiabandonados. Cotillean las fotos de los demás.

\section{El turismo y la red. Madrid.es}

A través de este trabajo, y como ya se ha podido ir comprobando, la tecnología ha adquirido una gran relevancia, rompiendo con los fundamentos tradicionales, y el sector turístico no se ha quedado atrás y ha recurrido a las tec- 


\begin{tabular}{|c|c|c|c|}
\hline Red & Aparición & Características & $\begin{array}{l}\text { \% conocimiento y } \\
\text { uso en España }\end{array}$ \\
\hline $\begin{array}{l}\text { Facebook } \\
\text { facebook }\end{array}$ & 2004 & $\begin{array}{l}\text { - Red más común y con mayor porción de seguidores. } \\
\text { - Usuarios mayoritarios: edad entre } 20 \text { y } 35 \text { años. } \\
\text { - } 600.000 \text { nuevos usuarios cada día. } \\
\text { - Permite crear grupos de interés. } \\
\text { - } 52.000 \text { pequeñas aplicaciones y } 140 \text { nuevas que se } \\
\text { crean cada día. } \\
\text { - Permite subir fotos y vídeos, y ser comentados en } \\
\text { cualquier momento. } \\
\text { - Red favorita para el } 38 \% \text { de los usuarios de redes. } \\
\text { - Primera red social tanto en España como Estados } \\
\text { Unidos (rankings Alexa, Compete y QuantCast, 2010) } \\
\text { - Red internacional, seria, original y tal vez con mayor } \\
\text { futuro que otras. }\end{array}$ & \begin{tabular}{|l|l}
$63,85 \%$ \\
\end{tabular} \\
\hline $\begin{array}{l}\text { Myspace } \\
\text { Maep myspacee } \\
\text { aplace tortriends }\end{array}$ & 2007 & $\begin{array}{l}\text { - Usuarios mayoritarios: entre } 26 \text { y } 40 \text { años (mayor } \\
\text { porcentaje entre } 26-30 \text { años). } \\
\text { - Mayor proporción de mujeres ( } 54 \% \text { ) } \\
\text { - Tercera red favorita. } \\
\text {-Incluye redes de amigos, blogs, fotografias, vídeos y } \\
\text { música. } \\
\text { - Diferencia perfiles entre usuarios convencionales y } \\
\text { artistas/cantantes. } \\
\text { - Red con mayor número de registrados del mundo. } \\
\text { - Plataforma musical y medio de promoción. }\end{array}$ & $45,28 \%$ \\
\hline $\begin{array}{l}\text { Windows live } \\
\text { Windows Live } \\
\text { Spaces }\end{array}$ & 2007 & $\begin{array}{l}\text { - Mayor número de mujeres }(52,12 \%) \\
\text { - Mayor proporción de pioneros. } \\
\text { - Red integrada, multimedia e internacional. } \\
\text { - Blogs, fotos, listas, amigos, perfil, libro (para hacer } \\
\text { comentarios). }\end{array}$ & $42,11 \%$ \\
\hline (i) tuenti & 2006 & $\begin{array}{l}\text { - Red con usuarios más jóvenes: } 75 \% \text { entre } 16-25 \text { años; } \\
\text { el } 42 \% \text { entre } 16-20 \text { años. } \\
\text { - Segunda red favorita de usuarios de redes }(23,5 \%) \\
\text { - Red adolescente, lúdica y tal vez menos mediática. }\end{array}$ & $36,54 \%$ \\
\hline XING & 2003 & $\begin{array}{l}\text { - Funciones básicas gratuítas y añadidas de pago. } \\
\text { - Oferta de descuentos y bolsa de trabajo. } \\
\text { - Gestión de contactos, mensajes, foros, agenda personal } \\
\text { y publicación y gestión de eventos. }\end{array}$ & $14,5 \%$ \\
\hline $\begin{array}{l}\text { Linked in } \\
\text { Linked in. }\end{array}$ & 2003 & $\begin{array}{l}\text { - Mayor número de hombres }(65,3 \%) \\
\text { - Mayores de } 30 \text { años. } \\
\text { - Red profesional, adulta y más exclusiva. }\end{array}$ & $7,75 \%$ \\
\hline twitter & 2006 & $\begin{array}{l}\text { - Usuario: persona adulta. } \\
\text { - Sólo el } 11 \% \text { de los usuarios tienen entre } 12 \text { y } 17 \text { años. } \\
\text { - Seguimiento de eventos en directo, la retransmisión de } \\
\text { charlas y ponencias a las que poca gente tiene acceso, el } \\
\text { intercambio de opiniones durante un evento en el que la } \\
\text { gente asiste como público o incluso comentarios sobre } \\
\text { películas o debates retransmitidos por la televisión. }\end{array}$ & $6,85 \%$ \\
\hline
\end{tabular}

Tabla 1: Principales redes sociales, características y difusión. Fuente: Elaboración propia a partir de Zed digital 2008

nologías de la información y la comunicación (TIC's), ante las exigencias de un cliente con mayores demandas y mayor conocimiento. Principalmente gracias a Internet como nuevo mediador, con una doble función de distribuidor de productos turísticos y como gestor de servicios a empresas relacionadas con el sector turístico. Se produce un cambio en la forma de entender la economía aplicada a la comercialización turística, donde se hace especial hincapié en lo inmaterial (información distribuida rápidamente por la red, con costes muy reducidos); en la cadena tradicional de los intermediarios (tour operadores, agencias de viaje) se reemplazan por páginas Web que permiten el acceso a toda la información, y los precios llegan a ser transparentes y dinámicos (Lanquar, 2001).

Los diferentes agentes del sector turístico son conscientes de la importancia que el turismo tiene para una economía, y más en el caso de España, $3^{\circ}$ destino mundial en recepción de turistas (52,2 millones), después de Francia (79 millones) y Estados Unidos (54,9 millones), y el $2^{\circ}$ destino mundial de ingresos por turismo con 61.600 millones de dólares, después de Estados Unidos, y donde más del $15 \%$ de empresas y el $20 \%$ de los trabajadores están relacionados con el sector turístico (Organización Mundial del Turismo -OMT-, 2009). Por ello, una rápida difusión de la información turística es imprescindible, siendo Internet la solución más eficaz: acceso a mayor número de canales y/o clientes a un menor coste. De ahí el énfasis de empresas y organismos turísticos en invertir un mayor presupuesto en tecnología e innovación.

Internet juega un importante papel a nivel turístico como herramienta de promoción y comercialización, ofreciendo al sector gran facilidad en la modificación y actualización de la información (Galí, Majó y Vidal, 2000), ya sea a través de la propia página web, blogs, folletos electrónicos, foros, redes sociales y demás integrantes de la web 2.0 mencionados al principio de este artículo. Por todo ello, expertos en turismo instan a las empresas a apostar por Internet, catalogándola como una "excelente oportunidad para las empresas turísticas a la hora de interactuar con sus potenciales clientes e incrementar sus ventas" (VI Foro de Turismo organizado por Turismo Rías Baixas, 2010).

El perfil del consumidor turístico ha cambiado, siendo un cliente más informado -puede acceder a gran cantidad de información en poco tiempo- y dispuesto a crear su propio viaje, siendo Internet el medio más utilizado para ello.

El concepto de producto, servicio, o mismo, destino turístico está evolucionando, por ello paralelamente a dicha evolución, las organizaciones turísticas deben de adaptarse y beneficiarse de las posibilidades que las redes sociales y la Web 2.0 les brindan. Se les abre una gran oportunidad de crear marca, saber lo que piensan los usuarios, incrementar las ventas gracias a la información, independientemente del tamaño de la empresa

(sea una pequeña empresa turística o una empresa líder a nivel nacional). Aunque el producto/servicio turístico ha evolucionado, la esencia continua siendo la misma, es decir, realizar un viaje o estancia, lo que realmente ha cambiado es la forma en que éste llega al cliente (Pons, 2009). Se toma por ejemplo un vídeo de un hotel subido en youtube: el hotel es el mismo, pero lo que era impensable es que el potencial cliente pudiese verlo en profundidad y leer comentarios y opiniones de otros usuarios, antes de su estancia en el mismo.

Dado que Internet está siendo utilizada de un modo creciente por parte de la sociedad, principalmente por jóvenes, se abre a nuevos potenciales clientes a corto y medio plazo. El avance en el uso de tecnologías por parte de los consumidores es más rápido que el de las empresas, pasando de la web 1.0 (consultas de folletos virtuales en internet) en la década de 1990, a la web 2.0 (compra del viaje, comentarios sobre el mismo, subida de fotografías y vídeos), en menos de 20 años (Pons, 2009). La evolución por parte de los agentes turísticos debe ser inmediato, e incluso, deberían optar por estrategias proactivas para anticiparse, si es que quieren sobrevivir en el actual mercado turístico.

El cambio en el modo de promocionar o dar a conocer un organismo turístico es uno de los actuales objetivos de 
la mayor parte de empresas del sector. Por ello, el sector turístico también ha recurrido a la utilización de la web 2.0, entendida como evolución de las ya citadas www. El concepto de web 2.0 aplicado al ámbito del turismo viene impulsado por la ya mencionada relación empresa-cliente, la cual está cambiando a raíz del mayor acceso de información por parte del cliente e interacción con otros potenciales usuarios a través de foros, blogs u otras herramientas de esta nueva tendencia (Instituto Tecnológico Hotelero, 2007).

Así aparecen nuevas clasificaciones o tipologías dentro del fenómeno 2.0. en el campo del turismo, como puede ser el Travel 2.0 (enfocado a viajeros) o el Turismo

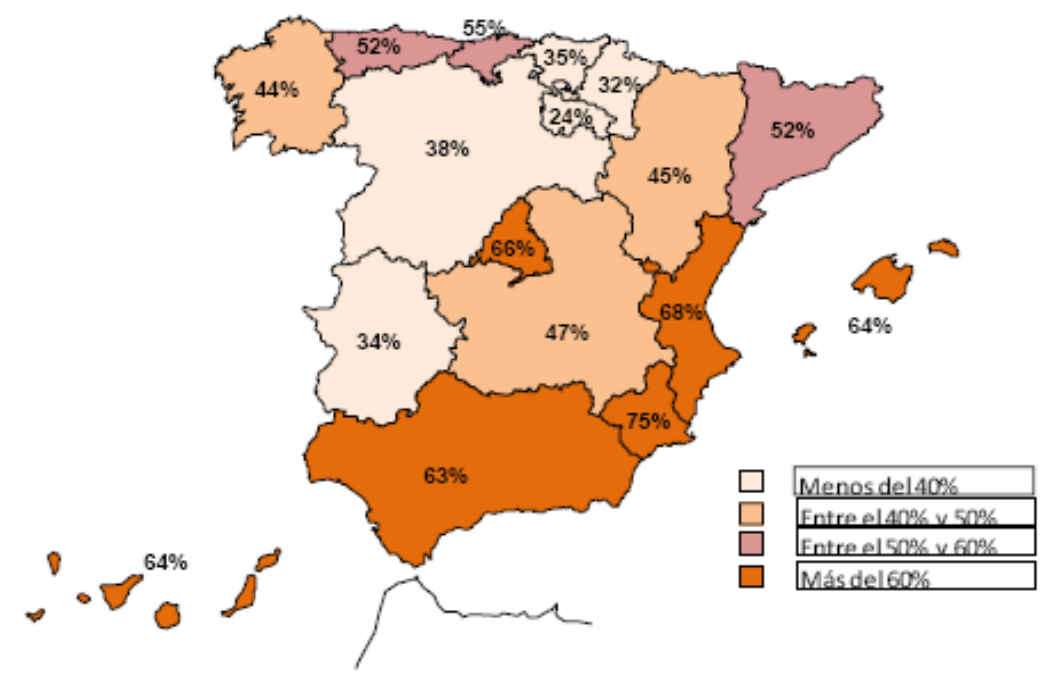

Gráfico 3: Porcentaje de uso de Internet de los turistas que visitan España, según comunidad autónoma de destino principal. Fuente: IET, Encuesta de Gasto Turístico (Egatur), 2009b
2.0 (enfocado a este sector), que a la vez recoge subcampos como el Turismo Rural 2.0, Hoteles 2.0, Agencias 2.0 o Mayoristas 2.0 entre otros, según la interacción que se produzca entre los usuarios o potenciales turistas y el tipo de turismo en el que estén interesados (Instituto Tecnológico Hotelero, 2007).

Internet proporciona infinidad de información a un solo click de ratón, pudiendo buscar la opción más económica y atractiva, a la vez que opiniones de otros turistas que ya han visitado un destino o vivido una experiencia turística. Por ello, más del $65 \%$ de los españoles ya organizan y reservan sus viajes vía Internet, porcentaje que se cree todavía en aumento (Hosteltur, 2009). Datos que refuerzan dicha afirmación muestran que en los últimos años el uso de Internet se ha ido incrementando a la hora de llevar a cabo la organización y preparación de los viajes en España por parte de los turistas residentes, así en 2008 el porcentaje era de $12,5 \%$, y en 2009 se había incrementado un $5 \%$ más. Los usuarios que utilizaron Internet en 2010 lo hicieron principalmente para la búsqueda de información $(96,1 \%)$ y la realización de algún tipo de reserva $(67,2 \%)$, tendencias similares a años anteriores (Instituto de Estudios Turísticos -IET-, 2009a).

Si dicho análisis se realiza en función de los turistas que visitan España, se observa que como viene ocurriendo desde 2007, la mayoría de ellos hacen uso de Internet en alguna medida para planificar su viaje (IET, 2009b). Como se puede observar en el siguiente gráfico, los turistas, según la comunidad autónoma de destino principal, usan más Internet cuando los destinos son aquellas comunidades con mayores llegadas de turistas, como es el caso de Murcia (el 75\% de los turistas no residentes con destino principal en esta comunidad usaron Internet). Con porcentajes por encima de la media del $60 \%$ aparecen por este orden: Valencia, Madrid, Andalucía y los dos archipiélagos.

Sea cual sea la tipología de turismo objeto de interés del turista, el fenómeno 2.0 ha puesto al alcance del sector turístico, una serie de herramientas que facilitan la elección y configuración del destino por parte de sus consumidores: nuevos canales, soportes y nuevas formas de promocionarse y llegar al cliente potencial.

Dentro de estas herramientas, las más recurridas son las redes sociales, lo que puede parecer obvio y sencillo, pero requiere un gran esfuerzo por parte de la empresa turística, ya que no es sólo el estar presentes, sino, el actualizarse continuamente e interactuar con los clientes o potenciales clientes.

Cuanto mayor sea la participación del cliente, mayor contenido tendrá la red y mayor será la fidelización del mismo. El resultado o beneficio no se verá a corto plazo con un incremento de las ventas de forma inmediata, lo cual hace que muchos empresarios sean reacios al uso de dichas redes. El resultado inmediato será la mejora de la reputación y generación de confianza en el potencial consumidor (Sobejano, 2009). El gran valor de estas redes o comunidades virtuales está en igualar la empresa a sus clientes (Sobejano, 2009), es decir, llegar a crear tal valor que por una parte el propio cliente se identifique y participe con la empresa, y por otro, la empresa recoja todas las ideas que el cliente proporcione o surjan en comentarios a través de la propia red.

Hasta ahora, el mercado de las redes sociales ha estado dominado por las redes ya mencionadas anteriormente como myspace, facebook o tuenti, y el sector turístico ha hecho también uso de las mismas creando perfiles, grupos y eventos vinculados con su empresa u organización. En el caso de facebook son numerosas las grandes cadenas o empresas hoteleras que poseen perfil que mandan información a sus fans -usuario de una red social que acepta formar parte de un grupo u perfil, pudiendo intercambiar información entre ambos- sobre los diversos eventos que van organizando-. Pero no sólo las grandes empresas hacen uso de esta red, sino que también lo hacen pequeños 
hoteles, además de ayuntamientos, agencias de viajes, tour operadores y toda empresa vinculada al sector, dado que es un medio al que un gran número de personas tienen acceso.

Aunque la tendencia sigue siendo el utilizar estas redes generalistas, ya que son a través de las cuales se puede acceder a un mayor número de usuarios, se empiezan a mostrar signos de decantación por otras más verticales y segmentadas (Roca, 2008). Así, van apareciendo redes/ comunidades especializadas en el sector, entre las que se señalan a modo de ejemplo y diversidad las siguientes:

- Turismo 2.0, tal y como se define en la propia web, es una red social del sector turístico enfocada a profesionales del turismo y/o viajes. Actualmente cuenta con 10.092 usuarios (febrero 2011), y entre los apartados destacados de la misma están los blogs, debates, fotos, vídeos, publicidad y un chat propio para usuarios registrados.

- Magic amigos es una red social del sector turístico todavía más segmentada que la anterior, ya que es la red social del Grupo Magic Costa Blanca, cadena hotelera innovadora con más de 30 años de experiencia, 15 de ellos en España, que cuenta actualmente con 1.377 miembros registrados (febrero 2011). A través de esta red, los usuarios pueden compartir vídeos, fotos o comentarios en sus foros con otros amigos de Magic Costa Blanca.

- En lo que respecta a couchsurfing, estamos hablando de una red para hacer conexiones entre viajeros y las comunidades que visitan. A través de ella se conectan entre sí más de 2.500 .000 personas de 246 países y más de 80.000 ciudades del mundo (febrero 2011). Los usuarios de esta red incluso ofrecen sus casas para visitantes o sus servicios de guía y si alguien no quiere recibir en su propia casa a un viajero puede orientarlo o hacerle recomendaciones, concepto que deriva de los años 60 del Club de Intercambio de Residencias - iniciativa según la cual dos familias de cualquier parte del mundo se ponían de acuerdo para intercambiar sus residencias durante sus vacaciones, ahorrándose así el alojamiento- (Ascanio, 2007). Entre sus apartados destacados encontramos mensajería propia para usuarios, grupos, eventos y testimonios de usuarios.

Tras revisar la situación actual del fenómeno 2.0 y su aplicación y uso en el sector turístico, se cree relevante estudiar un caso concreto que ejemplifique las tendencias expuestas. Por ello, se procede a analizar el uso de la web 2.0 por parte de la Comunidad de Madrid, web con prácticamente dos años de funcionamiento desde su inauguración: www.turismomadrid.es. Las razones que han llevado a tal elección son el ser una iniciativa pionera en cuanto a estrategia comunicativa a nivel nacional, el contar con un significativo número de seguidores en varias de las herramientas que integran como parte de la mismablogosfera, con 14.000 seguidores actualmente o facebook, con 12.521 fans- y la proyección de Madrid como una de las ciudades más visionada en la web 2.0 tras el lanzamiento de la misma (Turismo Madrid, 2010), llegando a equipararse a destinos como Philadelphia y los Ángeles a través de su uso de la red social foursquare, posicionándose Madrid como uno de los 10 destinos que mejor utiliza dicha red de promoción turística, hecho destacado, ya que esta red social en España tiene un desarrollo mucho menor que en Estados Unidos (About Foursquare, 2010).

La web turística del ayuntamiento de Madrid con formato 2.0 fue creada en enero de 2009 con el objetivo de convertirse en caso práctico de éxito en cuanto a la comunicación 2.0 en el sector turístico. Tal web surgió como parte de las nuevas acciones comunicativas y estrategia online de Turismo Madrid, apostando por el concepto 2.0 e integrando los canales de la red social en los que participa, posibilidades de comercialización y un nuevo estilo de informar más periodístico. Todo ello con el propósito de llegar a ser un referente como informador turístico de Madrid, ofertando una extensa cartera de servicios turísticos para todo aquél que esté interesado en viajar la Comunidad de Madrid, a través de su inserción en redes sociales y blogosfera -que permite al usuario tomar decisiones de compra en la misma página: reservar hoteles, comprar entradas para espectáculos, reservar sus vuelos,... - (Turismo de Madrid, 2010).

El lema o slogan de la web es "Madrid, about you" y cuenta con 7 menús que aportan variada información sobre la ciudad y actividades celebradas en la misma:

- Inicio: podemos encontrar las últimas noticias de la ciudad, una guía práctica, acceso a los últimos comentarios de facebook, un apartado de reservas y accesos directos a todas las herramientas 2.0 en las que está presente.: facebook, twitter, blog, flicker, mashup y delicius.

- Agenda: aparecen los eventos que se celebran cada día en la ciudad con previsión hasta mayo de 2011 -aproximadamente tres meses desde la fecha actual(espectáculos, musicales, exposiciones, eventos deportivos o teatro, entre otros).

- Buscaplanes: permite elaborar planes en la ciudad, filtrando los datos en función de los grupos familia, mayores, estudiantes, amigos y LGTB, el tipo de actividad y la fecha.

- Guías: permite descargarse las guías oficiales de la ciudad (compras, noche, gastronomía y cultura).

- Mapas: mapa de Madrid a través de Google Maps, así como descarga de planos de transporte u otros municipios cercanos.

- Fotos y vídeos: accesos a flicker y youtube para visionar las fotografías y vídeos vinculados a la ciudad.

- Mad\&you: permite registrarse y acceder a las mejores recomendaciones de ocio y a promociones exclusivas a través de su página en Facebook y/o boletín electrónico.

\section{Análisis de los resultados e implicaciones}

Para el análisis de la Web 2.0 de Madrid, se opta por realizar un estudio de contenido en base a los dos ejes cen- 
trales, es decir, las redes sociales y los blogs. Para ello se establecen las principales características de cada elemento, así como la incidencia y difusión de los mismos a través del número de usuarios, grupos o visitas. Esto, permite poder obtener datos tanto cualitativos como cuantitativos que faciliten la extracción y comparación de resultados con otras Web de turismo o elementos del 2.0, que poseen mayor número de usuarios, es decir, la web de la Comunidad de Murcia, de la Comunidad Valenciana, de Andalucía y la de los archipiélagos.

Si se toma como punto de partida las redes sociales,

\begin{tabular}{|c|c|c|c|}
\hline $\begin{array}{c}\text { Redes } \\
\text { Sociales }\end{array}$ & Función & Características & Usuarios \\
\hline Facebook & $\begin{array}{llr}\text { Permite la difusión } & \text { de } \\
\text { contenidos además } & \text { de } \\
\text { "conocer" de cerca } & \text { las } \\
\text { diferentes actividades } & \text { de } \\
\text { Turismo Madrid } & \end{array}$ & $\begin{array}{l}\text { - Enlace directo desde: la propia Web y } \\
\text { blogs (blogaboutmadrid.es } \\
\text { pasaenmadrid.com). } \\
\text { Fecha de creación: enero 2009. } \\
\text { - Estructura: Hola (página } \\
\text { presentación), muro (donde se van } \\
\text { publicando las novedades y los } \\
\text { seguidores dejan sus comentarios), } \\
\text { eventos, fotos y enlaces. Posee una } \\
\text { pestaña con herramientas: acceso a } \\
\text { youtube y flicker, vídeos y notas. }\end{array}$ & 14.322 amigos \\
\hline Twit & $\begin{array}{l}\text { El } 70 \% \text { de los seguidores son } \\
\text { profesionales del sector } \\
\text { turístico y comunicación on } \\
\text { line a nivel nacional e } \\
\text { internacional }\end{array}$ & $\begin{array}{l}\text { - Enlace directo desde: la propia Web } \\
\text { y blogs (blogaboutmadrid.es y } \\
\text { pasaenmadrid.com). } \\
\text { - Fecha de creación: enero } 2009 . \\
\text { - Más de } 3.619 \text { tweets. } 2.261 \\
\text { followings y } 377 \text { listados }\end{array}$ & $\begin{array}{l}4.902 \\
\text { seguidores }\end{array}$ \\
\hline Flickr & $\begin{array}{l}\text { Álbum de fotos online para la } \\
\text { difusión de imágenes de las } \\
\text { acciones y eventos que } \\
\text { organiza Turismo Madrid. }\end{array}$ & $\begin{array}{l}\text { - Enlace directo desde la propia Web y } \\
\text { blogs (blogaboutmadrid.es } \\
\text { pasaenmadrid.com). } \\
\text { - Fecha de creación: enero } 2009 \text {. } \\
\text { - } 18 \text { páginas con más de } 326 \text { ítems, } \\
\text { estructurados en más de } 42 \text { álbumes } \\
\text { con temas variados. } \\
\text { - Estructura: colecciones, album, } \\
\text { exposiciones, tags, personas, archivos y } \\
\text { favoritos. Destacar que hay acceso a } \\
\text { archivos desde 2002. }\end{array}$ & $\begin{array}{l}28 \text { contactos y } \\
10 \text { grupos }\end{array}$ \\
\hline Youtube & $\begin{array}{l}\text { Permite ver vídeos de Madrid } \\
\text { (campañas publicitarias, } \\
\text { eventos, zonas de Madrid, } \\
\text { recursos turísticos...) }\end{array}$ & $\begin{array}{l}\text { - Enlace directo desde la página de } \\
\text { facebook. } \\
\text { - Fecha de creación:enero } 2009 \text {. } \\
\text { - Canal propio de youtube: Canal } \\
\text { MADRIDTURISMO. } \\
\text { - Son un total de } 20 \text { vídeos sobre } \\
\text { Madrid. Ha recibido } 566 \text { exhibiciones } \\
\text { del canal y más de } 2750 \text { sobre el } \\
\text { material. Con } 8 \text { inscritos. }\end{array}$ & $\begin{array}{l}566 \\
\text { exhibiciones } \\
\text { del canal y } \\
\text { más de } 2750 \\
\text { sobre } \quad \text { el } \\
\text { material. Con } \\
8 \text { inscritos }\end{array}$ \\
\hline Mashup & $\begin{array}{l}\text { Reúne y da difusión a todos } \\
\text { aquellos contenidos online que } \\
\text { promocionan la actividad } \\
\text { turística en la Comunidad de } \\
\text { Madrid en la Red, permitiendo } \\
\text { realizar comentarios, } \\
\text { compartir informaciones o dar } \\
\text { opiniones. }\end{array}$ & $\begin{array}{l}\text { - Estructura: divide la información en } \\
\text { lugares mad about Madrid, agenda, } \\
\text { arte y cultura, noche y concierto, } \\
\text { gastronomía, ocio y compras, turismo } \\
\text { accesible, aire libre y deportes. }\end{array}$ & 286 amigos \\
\hline Delicious & $\begin{array}{l}\text { Marcador social que potencia } \\
\text { los contenidos turísticos de la } \\
\text { región mediante } \\
\text { recomendaciones de hoteles, } \\
\text { restaurantes, lugares de ocio y } \\
\text { establece una red de contacto } \\
\text { con usuarios que comparten } \\
\text { los mismos intereses. }\end{array}$ & $\begin{array}{l}\text { - Enlace directo desde la web oficial y } \\
\text { blogs (blogaboutmadrid.es } \\
\text { pasaenmadrid.com). } \\
\text { - Fecha de creación: enero } 2009 . \\
\text { - Estructura: bookmarks, } \\
\text { network, tags y suscriptores. } \\
\text { - Principales tags son: turismo, Madrid, } \\
\text { viajes, } 2.0 \ldots\end{array}$ & $\begin{array}{l}121 \\
\text { Bookmarks, } \\
2400 \text { networks } \\
\text { y } 159 \text { tags. }\end{array}$ \\
\hline
\end{tabular}

Tabla 2: Análisis de la Web Madrid 2.0. Fuente: elaboración propia, datos a febrero de 2011 


\begin{tabular}{|c|c|c|c|c|c|}
\hline Blogs & \multicolumn{2}{|l|}{ Función } & \multicolumn{2}{|c|}{ Características } & $\begin{array}{c}\text { Usuarios o } \\
\text { divulgación }\end{array}$ \\
\hline $\begin{array}{l}\text { BLOG about } \\
\text { MADZID }\end{array}$ & \multicolumn{2}{|c|}{$\begin{array}{l}\text { Blog que aporta información } \\
\text { de actualidad turística en la } \\
\text { Comunidad de Madrid. }\end{array}$} & \multicolumn{2}{|c|}{$\begin{array}{l}\text { - Enlace directo desde la web oficial y } \\
\text { blog pasaenmadrid.com. } \\
\text { - Estructura: pantalla de inicio donde } \\
\text { aparecen las últimas entradas, así como } \\
\text { un menú de categorías (actividades, } \\
\text { arte, viajes, eventos, cultura...) y } \\
\text { acceso al resto de herramientas 2.0: } \\
\text { facebook, Twitter, delicious, flicker y } \\
\text { el segundo blog oficial. En la parte } \\
\text { superior aparece un menú a través del } \\
\text { cual se puede acceder a información } \\
\text { sobre los gestores del blog, a un } \\
\text { blogroll (enlaces a otros blogs), } \\
\text { contacto y finalmente un acceso a la } \\
\text { web oficial madridturismo.com } \\
\text { - Temática: cultura, viajes, turismo, } \\
\text { eventos, fiestas, gastronomía y toda } \\
\text { actividad vinculada al ocio y recreación } \\
\text { de la ciudad de Madrid. }\end{array}$} & $\begin{array}{l}\text { El blog tiene } \\
\text { una media de } \\
3.600 \text { visitas } \\
\text { mensuales }\end{array}$ \\
\hline $\begin{array}{l}\text { Blog Pasa en } \\
\text { Madrid }\end{array}$ & \multicolumn{2}{|c|}{$\begin{array}{l}\text { Reúne información de } \\
\text { referencia en Internet sobre el } \\
\text { sector turístico facilitando la } \\
\text { búsqueda a los usuarios. }\end{array}$} & \multicolumn{2}{|c|}{$\begin{array}{l}\text { - Enlace directo desde la web oficial y } \\
\text { blogaboutmadrid.es. } \\
\text { - Estructura: pantalla de inicio donde } \\
\text { van apareciendo las entradas, contacto } \\
\text { y quiénes somos. Se encuentra al igual } \\
\text { que el anterior un blogroll, accesos } \\
\text { directo a las restantes herramientas } 2.0 \\
\text { y una lista de categorías. Como } \\
\text { novedad aparece un apartado de los } \\
\text { más leídos. } \\
\text { - Temática: agenda, arte y cultura, } \\
\text { noche y conciertos, gastronomía, ocio y } \\
\text { compras, turismo accesible, aire libre y } \\
\text { deportes. }\end{array}$} & $\begin{array}{ll}\text { Cuenta con } \\
\text { más de } 300 \\
\text { enlaces } \\
\text { entrantes }\end{array}$ \\
\hline Gestión & \multicolumn{5}{|c|}{\begin{tabular}{|l|l|l|} 
Función & Características & Oferta
\end{tabular}} \\
\hline Reserva ya! & $\begin{array}{l}\text { Poder realizar gestiones } \\
\text { de reserva y } \\
\text { contratación de diversos } \\
\text { componentes turísticos. }\end{array}$ & \multicolumn{2}{|c|}{ 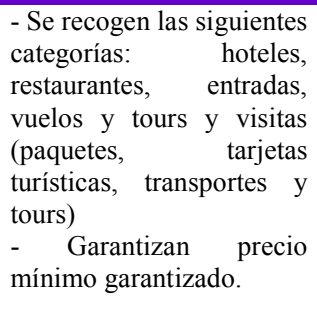 } & \multicolumn{2}{|c|}{$\begin{array}{l}\text { Más de } 1.000 \text { hoteles en toda la } \\
\text { comunidad. } \\
2.446 \text { restaurantes. } \\
118 \text { eventos para comprar entradas. } \\
\text { Enlace de vuelos con el buscador- } \\
\text { gestor Rumbo.es. Tarjetas de } \\
\text { transporte y turísticas tanto para } \\
\text { Madrid como Toledo. Tours a } 6 \\
\text { destinos con diferentes } \\
\text { combinaciones posibles. }\end{array}$} \\
\hline
\end{tabular}

Tabla 2 (continuación): Análisis de la Web Madrid 2.0. Fuente: elaboración propia, datos a febrero de 2011

éstas pueden ser agrupadas dos a dos según objetivos y funcionalidad. Facebook y Twitter son redes de comunicación e intercambio entre usuarios, profesionales o no, Fickr y Youtube se centran en la difusión de la imagen de la ciudad y lo que en ella acontece, mientras que Delicius y Mashup ya están focalizados al sector turístico y la oferta existente.

Analizando los resultados, se observa que las herramientas con mayor peso e incidencia son las redes sociales Facebook y Twitter, que en poco más de un año han llegado a más de 12.000 y 4.000 seguidores, respectivamente. En ambas, se comprueba que la estructura y formato está muy elaborado y ordenado, con actualizaciones constantes y vinculaciones a otras redes, blogs o eventos relacionados con Madrid 2.0. Con estas dos redes sociales, abarca a una gran parte del mercado objetivo, ya que posee contacto con usuarios reales y potenciales, así como con profesionales, que a través de dichas herramientas potencian el intercambio de información, opiniones y valoraciones.

En relación a la difusión de la imagen de Madrid, Youtube es el principal medio aunque es el más reciente, potenciado también por la creación del canal MadridTurismo, y los links existentes en las otras redes, blog o en la propia Web, que incrementan el número de exhibiciones. Destacar de Flickr, que tiene histórico desde 2002 y que recoge tanto imágenes de la ciudad, como de eventos culturales. El número de usuarios no es muy alto, no olvidar, que esta red es más utilizada por personal amateur o profesionales de la fotografía, y no tanto por usuarios no especializados. 
Para finalizar con las redes sociales, hablar de aquellas específicas de promoción y oferta turística, Delicius y Mashup, que ya no abarcan un número muy amplio de usuarios dado el gran desconocimiento por parte del mismo y por su reciente creación. Además, aún no existe un gran número de recomendaciones de lugares, establecimientos o eventos inscritos, por lo que el número de opiniones también es reducido.

Tomando como referencia los blogs, una herramienta novedosa y no muy extendida en las webs de destinos turísticos, destaca la complementación en el diseño de ambos, abarcando informaciones interesantes tanto para usuarios, reales o potenciales, como para empresas y organismos relacionados con el sector. Blog About Madrid, que engloba temas vinculados directa o indirectamente al turismo en la comunidad, posee más de 3.500 entradas mensuales de media, mientras que Blog Pasa en Madrid, ofrece más de 300 enlaces que proporcionan información de referencia sobre el sector.

Por último, y no menos importante, destacar los recursos disponibles para gestionar y reservar diferentes elementos turísticos, caso de hoteles, vuelos, restaurantes, entradas o visitas y tours. Dicha opción está disponible para todos los servicios turísticos de la Comunidad de Madrid y se puede acceder a ella desde la propia página inicial. Este elemento permanece de forma constante en el lateral derecho durante la navegación por la propia web. Resaltar el gran número de componentes turísticos ofertados y la variedad, tanto en el proceso de búsqueda como en el de clasificación según recursos, gustos o ámbito geográfico.

Este análisis deja claro que la web de turismo de la Comunidad de Madrid está realizando un gran esfuerzo en relación a las herramientas 2.0. Pero, ¿realmente es la pionera e innovadora en España? Para ello realizamos una comparativa con las principales webs turísticas de las comunidades que mayor uso poseen de Internet como medio de información o canal de gestión para el turista, es decir, la Comunidad de Murcia, Valencia, Andalucía, Baleares y Canarias, como quedó reflejado en el gráfico 3.

Como se puede observar en la tabla 3, las webs de Murcia y Valencia son las que mayor esfuerzo están realizando, con páginas muy dinámicas y accesos directos a numerosas herramientas de la 2.0, pero Murcia, además de los enlaces básicos a Facebook, Twitter y Youtube, aporta tres elementos que en el resto de páginas analizadas no están presentes, incluída la de Madrid. Uno de ellos, es el Minube que proporciona información y facilita la planificación sobre que ver y hacer, donde comer y dormir, además de tener un foro para preguntas y dudas. Similar a éste está también TripAdvisor, que posee las mismas funciones pero más ampliadas y que entre los usuarios de Internet tiene mayor difusión e influencia, además de su excelente posicionamiento en los buscadores. Por último hablar de Trivago, que es un comparador de precios de los principales gestores de oferta turística por Internet y facilita links a enlaces de noticias de Murcia, guías turísticas, fotos u opiniones de usuarios. En todos ellos, se pueden llevar a cabo procesos de reservas y compras.

Analizando cada una de las herramientas 2.0 observamos que Valencia y Canarias tienen un número muy elevado de seguidores de Facebook, que el más elaborado y estructurado es el de Valencia con apartados relevantes a nivel turístico como Valencia F1 o la Tomatina, y que ambos superan en número de amigos al de Madrid. Con Twitter la balanza se decanta a favor de Madrid, con mayor número de seguidores y tweets. Destacar que sólo Murcia y Valencia poseen canal de YouTube, en el que Murcia desenvuelve una gran actividad con más de 95 vídeos editados. Entre ellas también se reparten el uso de Picasa en la de Murcia y Flicker en la de Valencia.

Ninguna web posee enlaces directos a blogs, en el caso de la de Baleares no existe ninguna red o similar. Los blogs encontrados al no estar vinculados a la web de turismo, por lo general, proporcionan información variada donde el turismo no tiene por qué ser el eje central.

Por lo tanto, se puede afirmar que Murcia está realizando un mayor esfuerzo con una amplia gama de recursos que no poseen ninguna de las webs analizadas. Dicha tendencia es lógica, ya que no se puede olvidar que es la comunidad con mayor porcentaje de uso de Internet por los turistas extranjeros que visitan España (75\%). En detrimento, Madrid posee herramientas de gran dinamismo y generadoras de información, que son los 2 blogs oficiales, proporcionando el enlace a los mismos desde la página principal y desde las otras redes, así como el buscador propio de reservas de recursos turísticos. Destaca el bajo esfuerzo realizado por las comunidades restantes, a excepción de Valencia, en comparación al porcentaje de usuarios de Internet que manejan, principalmente Baleares y Canarias.

\section{Conclusiones}

No cabe duda de que Internet es un elemento clave para el sector turístico, que abarca desde funciones de marketing a distribución pasando por análisis de tendencias tanto del mercado como del turista. Pero un nuevo paso ya se ha dado y se ha instaurado en nuestra sociedad, la web 2.0, y con ella las redes sociales y blogs que están desafiando los modelos de funcionamiento tradicionales, y ya no sólo a nivel turístico sino en la sociedad en general. Sólo hace falta reflexionar en este principio de año 2011, donde países árabes están llevando a cabo revoluciones a favor de la democracia en las que Internet ha sido la semilla y las redes sociales el canal.

El mundo cambia, y el sector turístico, luego de años de escasas variaciones, está en un proceso de transformación continua, el turista es el que tiene el poder, ya no sólo el adquisitivo, sino que posee la capacidad de planificar, gestionar, y si no es de su agrado, compartirlo con todo aquel que tenga acceso a Internet, el boca-oído ahora tiene dimensiones incalculables y se transmite a través de un cable.

Algunos organismos y empresas han visualizado esta oportunidad de mercado que en breve se convertirá en exi- 


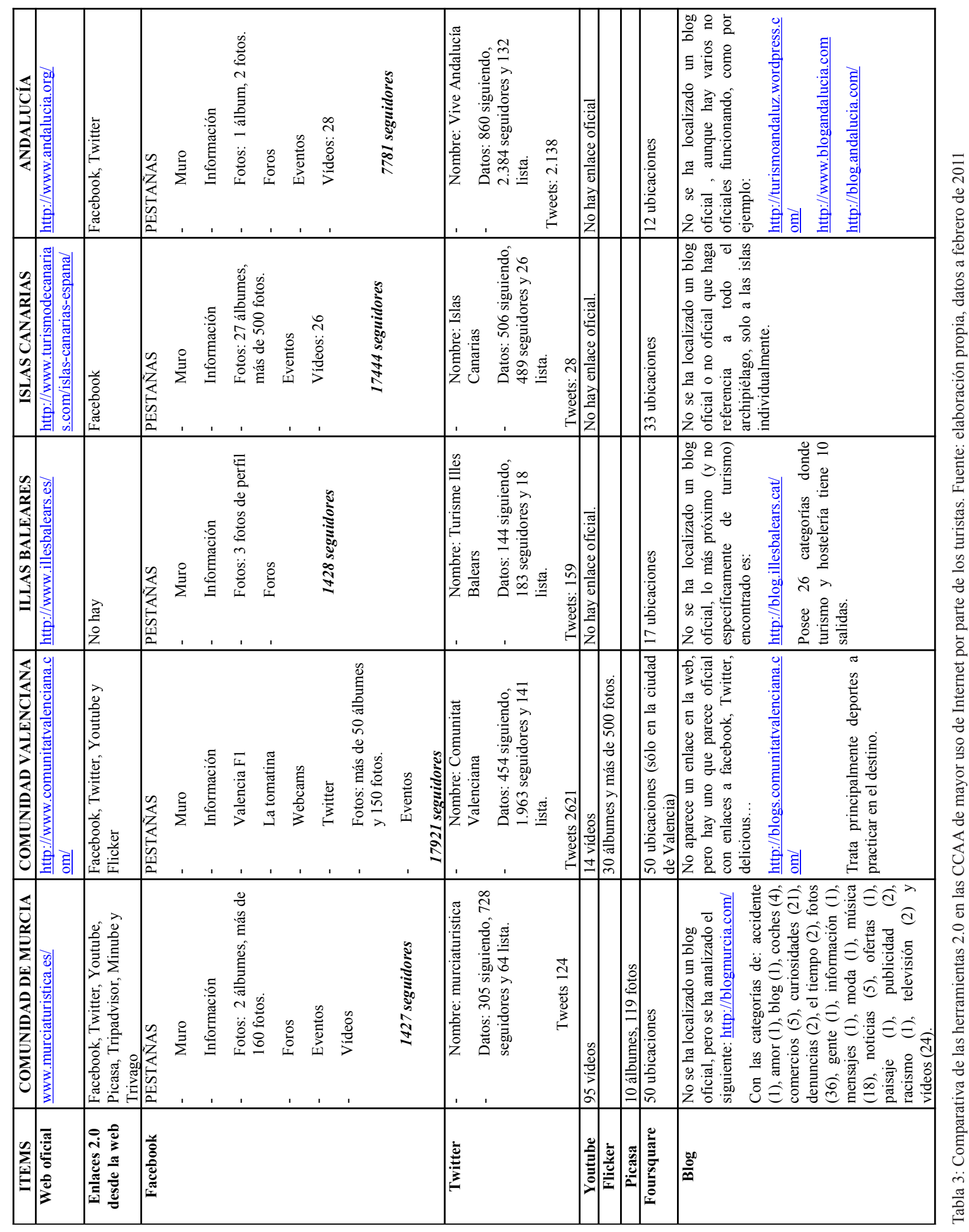


gencia básica, lo que ahora puede generar una ventaja, en tiempo limitado será una demanda obligatoria por parte del usuario. MadridTurismo está aprovechando dicha oportunidad y se encuentra trabajando en ello de forma constantes, y lo más importante, con continuidad. En dos años escasos han cambiado estructura, contenidos, herramientas, pero lo más importante, han mejorado la forma de interactuar con los usuarios; ésta ya no es estática, del contenido al receptos, sino que está impregnada de un dinamismo continuo que genera retroalimentación del demandante o cliente al oferente.

Madrid ya se ha subido al tren 2.0, teniendo por ahora tiempo para seguir mejorando e incrementando las utilidades, lo que le aporta una ventaja que otros muchos ya no han conseguido o simplemente no han intentando conseguir. Se propone trabajar principalmente en los siguientes aspectos de mejora:

- Partiendo de la página principal, ésta tendría una mayor optimización de recursos si pudiera proporcionar un diseño más intuitivo. Intentar seleccionar la información de mayor relevancia para presentar una estructura más clara y limpia sin que el usuario tenga una sobresaturación de información, es decir, eliminar en lo posible el ruido visual.

- Sería muy interesante y beneficioso para el usuario que en la web estuvieran disponibles enlaces a redes turísticas como TripAdvisor o Mi Nube, que proporcionan información y posibilitan la planificación a la hora de comer, de dormir o sobre qué hacer en un destino turístico. Además, ambas redes poseen gran difusión y permiten una gran interactuación con el usuario, dado que estos aportan gran parte del contenido a través de sus opiniones.

- Otro elemento que en los últimos tiempos está teniendo una gran repercusión, y por lo tanto, incremento de usuarios, es Trivago, un comparador de precios de los principales gestores de oferta turística. Además, esta herramienta permite el enlace a noticias, guías turísticas, fotos u opiniones de otros usuarios. Sería bueno la inclusión de dicha herramienta en la web.

- En relación a Facebook, aunque es un elemento muy cuidado por parte de TurismoMadrid, una posible mejora sería la creación de apartados donde recoger los acontecimientos más relevantes a nivel turístico, qué visitar de forma sintetizada u ofertas turísticas.

Es muy importante tener presente que el mundo 2.0 es muy veloz y el no estar actualizado, o demorar en el proceso, disminuye las posibilidades de alcanzar un buen posicionamiento. La web 2.0 ya es más que una realidad.

\section{Bibliografía}

AGN, Agencia Pontevedra

2009 "Expertos en turismo instan a las empresas a apostar por Internet”. Diario de Pontevedra, publicado el 30/03/2009. Disponible en: http://diariodepontevedra.galiciae.com/nova/28133.html (consultado el 30/05/2009).
AIMC (Asociación para la investigación de medios de comunicación)

2008 Navegantes en la red

Ascanio, A.

2007 "Proyecto Couch Surfing. Una red de intercambio de viajeros". PASOS, 5 (3): 407-408.

Asociación Española de Científicos e Investigadores en Turismo (AECIT)

2008 Los contenidos digitales en España. AECIT.

Best Relations

2009 Estudio "Redes Sociales 09"

Castells, M.

2006 La sociedad red: una visión global. Editorial Alianza.

Computer Industry Almanac

1999 "Computer Industry Almanac says over 364 million PCs-in-use worldwide year-end 1998”. Market Research Reports. Computer Industry Almanac Inc.

De Sola Pool, I. y Kochen, M.

1978 "Contacts and influence" Social Networks 1(1): 5-51. Diccionario de Internet.

2002 Diccionario de Internet. Editorial Complutense, Madrid.

Flanagin, A.J. y Metzger M.J.

2001 "Internet Use in the Contemporany Media Enviroment”. Human Communication Research, 27: 153-181.

Forrester Research

2009 Forrester Research's Consumer Technographics Data Fumero, A. y García, J.M.

2008. "Redes Sociales. Contextualización de un fenómeno "dos-punto-cero". Cuadernos de comunicación e innovación, 76: 56-68.

Fundación Orange

2008 Informe eEspaña: Informe anual sobre el desarrollo de la sociedad de la información en España.

Galí, N., Majó, J. y Vidal, D.

2000 "Patrimonio Cultural y Turismo: Nuevos modelos de promoción vía Internet". Cuadernos de Turismo, 6: 73-87.

Holme, P., Edling, C. y Liljeros, F.

2004 "Structure and time evolution of an Internet dating community". Social Networks, 26: 155-174.

Instituto de Estudios Turísticos (IET)

2009a Informe anual 2009. Encuesta de Movimientos Turísticos de los Españoles (Familitur). Ministerio de Industria, Turismo y Comercio.

Instituto de Estudios Turísticos (IET)

2009b Informe anual 2009. Encuesta de Movimientos Turísticos en Fronteras (Frontur) y Encuesta de Gasto Turístico (Egatur). Ministerio de Industria, Turismo y Comercio.

Instituto Tecnológico Hotelero (ITH)

2007 Memoria anual 2007

Instituto Tecnológico Hotelero (ITH) y Sociatec y Canal Empresarial

2009 Desarrollo de comunidades Sociales. Nuevas estrategias de posicionamiento, comercialización y fidelización. ITH, Sociatec y Canal Empresarial. 
iProfesional

2010 "Facebook cumple seis años y ya es el tercer "país" del mundo". iProfesional.com, publicado el 08/02/2010. Disponible en: http://www.iprofesional. com/notas/94039-Facebook-cumple-seis-anos-y-ya-es-el-tercer-pais-del-mundo.html (Consultado el 25/03/2010).

Kahn, R., Leiner, B.M., Cerd, V., Clark, D., Kleinrock, L., Lynch, D., Postel, J., Roberts, L. y Wolff, S.

1997 "The Evolution of the Internet as a Global Information System”. Intl. Inform \& Libr. Rev, 29: 129-151.

Karinthy, F.

1929 Chains

Lanquar, $\mathrm{R}$.

2001 Marketing turístico, Barcelona, Ariel Turismo, Colección AECIT.

Mediascope Europe

2010. Resultados de España. Febrero 2010. EIAA (Europe Interactive Advertising Asociation).

Morris, M. y Ogan, C.

1996 "The Internet as Mass Medium". Journal of Communication, 46.

Muñoz, X

2009 "Objetivo: la promoción a través de las redes sociales". Hosteltur, publicado el 26/05/2009.

Murolo, N.L.

2009 "Nuevas Pantallas frente al concepto de televisión. Un recorrido por usos y formatos".Razón y palabra, 69.

Noriega, A. y Jimenez, M.

2009 "El turista recurre a las TIC ante un cliente más informado". CincoDías.com, publicado el 20/03/2009. Disponible en: http://www.cincodias. com/articulo/empresas/turismo-recurre-TIC-clienteinformado/20090320cdscdiemp_19/cdsemp/ (consultado el 27/05/2009).

Papacharissi, Z. y Rubin, A. M.

2000 "Predictors of Internet Use". Journal of Broadcas ting \& Electronic Media, 1550-6878, 44 (2): 175-196.

Peñaranda, M., López, R., Quiñones, E. y López, J.J.

2006 "Los «Small Worlds" y el algoritmo de Floyd: una manera de estudiar la colaboración científica". Psicothema, 18 (1): 78-83.

RETREVO

2010 Retrevo Gadget Census 2010.

Roca, G.

2008 "Soluciones para nuevas realidades. Modelos de negocio en las redes sociales. TELOS, 76.

Ros-Martín, M.

2009 "Evolución de los servicios de redes sociales en Internet”. El profesional de la información, 18 (5)

Short, J., Ederyn, W. y Christie, B.

1976 The social psychology of telecommunications. London: Wiley.

Subrahmanyam, K., Reich, S.M., Waechter, N. y Espinoza,G.

2008 "Online and offline social Networks: use of social networking sites by emerging adults". Journal of ap- plied development psychology, 29 (6): 420-433.

Vila, J.

2009 "Análisis de las redes sociales: Facebook". Comunicación y pedagogía, 233: 22-26.

Watts, D. J.

2006 Seis grados de separación. La ciencia de las Redes en la Era del Acceso. Ed. Paidós/Transiciones, México.

Watts, D. J. y Strogatz, S. H.

1998 "Collective dynamics of 'small-world' networks.". Nature 393 (6684): 409-10

Zamora, M.

2006 "Redes Sociales en Internen". Maestros del Blog. Disponible en: http://www.maestrosdelweb.com/editorial/redessociales/ (Consultado 02/04/2010).

Zed digital

2008 El fenómeno de las Redes Sociales. Percepción, usos y publicidad. Zed digital

\section{Recursos electrónicos}

About Foursquare: http://www.aboutfoursquare.com Alegsa: http://www.alegsa.com.ar/Dic/internauta.php Blog de Jimmy Pons: http://jimmypons.typepad.com Blog de Juan Sobejano: http://www.juansobejano.com Couchsurfing: http://www.couchsurfing.org/ Hoteles Magic: http://hotelesmagic.ning.com/

Hosteltur: http://www.hosteltur.com/59082_65-espanoles-reserva-sus-viajes-internet-british-airways.html

OMT (Organización Mundial para el Turismo)

The Nielsen Company: http://es.nielsen.com

Turismo20: www.turismo20.com

Turismo Madrid: turismomadrid.es

VI Foro de Turismo Rías Baixas: http://www.finanzas. com/noticias/economia/2009-03-24/106230 foro-turismo-rias-baixas-analizara.html

Recibido:

$01 / 03 / 2011$

Reenviado:

$05 / 10 / 2011$

Aceptado:

$08 / 01 / 2012$

Sometido a evaluación por pares anónimos 